begin the volume by looking at Bob Brecher's essay 'Surrogacy, liberal individualism and the moral climate'.

JOHN HALDANE Lecturer, Department of Moral Philosophy Director of the Centre for Philosophy and Public Affairs,

University of St Andrews.

\section{Ethics - the Heart of Health Care}

\author{
David Seedhouse, 154 pages, \\ John Wiley and Sons, Great Britain, \\ $£ 8.95 \mathrm{pbk}, 1988$
}

This is a book in three parts. Part one concerns itself with the author's desire to demonstrate that there is a need for an increase in understanding of the ethical and moral nature of health care by those engaged in health care work. 'Work for health is a moral endeavour,' is the catch-phrase of this section of the book.

The rather more tortuous and longwinded second part of the book explores the author's understanding of attempts by a variety of philosophers, both classical and modern, to describe good health and health care. Whilst I found some chapters and parts of chapters in this section interesting, others were either over-simplistic or presented problems in such an idiosyncratic way as to tender them unrecognisable.

The third part of the book describes the use of the 'ethical grid', a device presumably of the author's creation, which is proposed as a framework onto which health care professionals and others can hang concepts when engaged in ethical debate. He describes and illustrates its working using two examples. This third section may be of interest to those who teach medical ethics to medical students and other health care students and professionals.
Ethics - the Heart of Health care has the strong proselytising style of the recent convert. This is most apparent in the early sections but continues throughout. The book explores the variety of philosophical positions and approaches currently on offer and concludes that none of them are sufficient. These are the wilderness chapters. In the final section we are led, hesitantly, to the ethical grid which, despite some disclaimers, was for this book, the promised land.

This is a curate's egg of a book, too basic for the serious medical ethicist and too complex for the uninitiated. I guess it will find its mark with the youthful, zealous, middle ground. Others might find it worth dipping into.

SIMON LUNDY Editorial Associate of the Journal of Medical Ethics and General Practitioner, Gallions Reach Health Centre, Thamesmead, London SE28 8BE. UMDS Lecturer,

Department of General Practice

\section{The Health Scandal: Your Health in Crisis}

Vernon Coleman, 245 pages, London, £12.95, Sidgwick and Jackson, 1988

Fourteen 'scandals' are listed as the symptoms, and the cause, of the decline in the health services and, according to Vernon Coleman, the cause of positive damage done to many hundreds and thousands of unwitting patients. Much of what he says has a grain of truth in it. There is, after all, something worrying about the BMA acting as the dispassionate spokesperson with the interests of the patients at heart when it is also the trades union of the doctors. But the same could undoubtedly be said for the Bar Council, or the Law Society, or for most other professional bodies.
There is a major question that hangs over all of them, and the area that should be most debated is that of openess to the public and general accountability, as well as the degree to which lay people are included in the decision-making processes, with their eyes always on the lookout for blatant self-interest.

That, of course, is a major ethical issue, but Coleman does not take it up because he is too concerned with having his own bash at the doctors, at what he regards, partly justifiably, as questionable prescribing habits, at the BMA's opposition to alternative medicine and, of course, its opposition to patients having access to their own medical records, a situation now at least partially reversed. But because he so loathes the BMA, he also attacks it for wanting more doctors, on the grounds, left unclear, that the public will not benefit from more doctors. The obvious question there is that it depends what the doctors are doing, whether they are working in arguably useless and certainly expensive hi-tech and experimental areas, or whether they are working in the field of chronic diseases of the elderly in an ageing population or with the dying, or with the chronically sick, all muchunderdoctored areas in the UK.

This book is too extreme to be much use, yet Coleman touches on some interesting areas. Joe Collier, himself a doctor, in his recently published book, The Health Conspiracy - How Doctors, the Drug Industry and the Government Undermine our Health, 1989, Century, 175 pages, £4.95) has covered many of the same areas. But his is an altogether more cogent and compelling presentation, all of which we can believe. Or most of it. Whether we will act upon the evidence is another matter altogether.

JULIA NEUBERGER Chairman, Patients' Association 